\title{
PRIVATE EQUITY INVESTMENT IN THE CZECH REPUBLIC
}

\author{
Alexej Sato*
}

\begin{abstract}
:
New principles, tasks and expectations for the nearest future, as well as upcoming development trends of private equity investments in global economy are mentioned in this paper. Ecological investments of private equity, as for example: alternative power engineering, biotechnologies or any other technologies, regardful to the living environment, appear to replace gradually foregoing investments focusing on information engineering and communication technologies. Attention of private equity funds seems to be paid especially on emerging markets during oncoming decade. Sources, aims and conditions of usage of private equity in Europe are not similar comparing with North America or Asia-Pacific region. While in the North America major-part of equity consists of private sources, Cohesion Funds of the European Community are frequently used for financing of funds in Europe. Consequently private equity is usually used for growth or expansion of a company or for "buy in - buy out" operations, scarcely any investments are focused on start-up and early stage projects in Europe. Recommendations of European Commission and EVCA regarding elimination of obstacles to private equity investments in Europe include:

- harmonization of tax and legal rules for private equity investments in the Member States of European Community,

- improvement of European tax and legal environments,

- move towards greater transparency of tax reporting.
\end{abstract}

Keywords: venture capital, private equity, private investors, investment funds, buy in - buy out operations, tax and legal environments.

JEL Classification: G24

\section{Introduction}

The recent global economic and financial crisis that affected also the economic system of the Czech Republic certainly was not an unexpected or accidental event as it is often presented. Symptoms of a possible collapse of the financial system were evident several years before the crisis and in the Czech Republic they were manifested in the form of offering cheap, easily accessible and usually insufficiently secured loans, mortgages and similar financial resources.

The main participants in the crisis of the financial sector in all countries were namely retail banking subjects, investment and mortgage banks with a substantial contribution of money market regulators including circulation banks and last but not least private rating agencies, as well. However, fund recipients with their irresponsibility also

* University of Economics, Prague, nám. W. Churchilla 4, CZ - 13067 Praha 3 (sato@ vse.cz). 
took part in the crisis: governments, lawmakers, regional authorities as well as end recipients. The development of the crisis itself was not surprising but it was rather the speed with which it occurred and spread outside the financial and economical sectors, nearly into all fields of social life.

The reaction to the mistakes and inconsistency that occurred in the financial sector was a considerable increase of regulation and supervision not only in the financial sector but also in the entire economic system. The question is to what extent the adopted regulation and control measures are adequate to the situation and if they also bring the expected effect in future.

In the Czech Republic, Slovakia, but also in the other countries of Central and East term Europe, the situation was and is not as serious as it was in the United States or in any other West European countries. However, thanks to close relations of the home bank sector with foreign banks, the global crises impacted and negatively influenced also the local financial market. Here, the global crisis spread to the local economic system namely through foreign trade, on which home economic systems are strongly dependant.

On the one hand, local banks reacted to the occurred situation understandably but in absolute contradiction to instant needs of entrepreneurial subjects and in contradiction with measures that could moderate development and consequences of the crisis. While the circulation banks retain or even decrease interest rates for many months, the commercial banks conversely make conditions for granting loans to their clients more restrictive and often more expensive.

As an option to overcome the more complicated access to traditional financial resources, certain alternative financial resources come into question - such as venture capital. The following paper is an attempt to verify this option by means of analysing the development of venture capital investments in the Czech Republic including the economic and legislative conditions for their entry. It indicates possibilities and perspectives of further development of these investments in both global and regional scales, estimates their contribution to solution of the crisis and introduces presumptions for their wider and more intensive utilisation in the internal economic system.

\section{Private Equity as an Alternative Form of Financing of Business Activities}

Due to economic reasons, the venture capital remained not only unused but also a quite unknown financial tool for home economists until the beginning of the nineties. The economic theory and experience in the Central and East European countries are still inconsistent in using concepts related with its investment. The concept of the venture capital is used as a synonym to the Anglo-American "private equity" although the concept of the "venture capital" in the international environment is often connected only with investments in the initial phases of this business activity. However, investment of the venture capital in the Czech Republic is always understood as a method of its entry, during which basic change of the structure or increase of the fixed assets occurs (e.g. see 
Sato, 2007, p. 236). Usually after entry of the venture capital, the investor becomes the majority owner, exceptionally he remains as a minority owner with the right of taking part in principal decisions of the company. Usually, he is not interested in administration of the company in executive and other managing issues. Entry of capital tend to be connected with formation of positive inter-personal relations of investor's representatives and capital recipient's management based on mutual partnership and sometimes it is also accompanied by expert personal assistance by the investor. Reason of such connection is utilisation of the synergic effect that should bring above-standard high increase of value of the investment funds. Investment of the venture capital is not only a single-shot financial operation but it assumes several years duration partner co-operation based on continuous and trustworthy evaluation of company 's development. If the company is not successful in its development, the investor will lose the invested funds without return; in case of a positive development the value of the invested investor's even minority share together with the initiator's business plan share is several times increased (e.g. see Dubocage, Rivaud-Danset, 2006, p. 19).

Entry of the investor takes place at any moment of the company's development: at the moment of its establishment, during development, expansion, but also in case of temporary or chronic financial problems. Because the venture capital funds use to be renown and financially strong subjects, the entry can also be accompanied by gaining possibilities of other financial help, for example in the form of loans, leasing or other forms that under normal conditions would be for the recipient inaccessible or that would be realised under not very attractive financial conditions (e.g. see EVCA, 2007, p. 23).

The aim of entry of the venture capital is to increase the value of the invested funds in the form of subsequent sale of the property share in the company, usually after three to five years of participation in the particular entrepreneurial subject. The sale can have a form of placing the company's shares at the stock exchange or their sale to a selected strategic partner, in some cases also to company's partners. Therefore, venture capital investors a priori choose such companies that are suitable for future placing the shares at the stock exchange or selling them to a strategic partner and during their engagement in the company, they purposefully orient its management to that intention (e.g. see Taušer, 2005, p. 224). Unlike the Czech Republic and the other Central and East European countries, developing a company for the purpose of its further sale under profitable conditions is a common business everywhere in the world. Sale of the share in the company often is the only way for the venture capital that enables to reach not only return but namely a high degree of increase of the value of the invested funds.

Development of venture capital funds was noticed in a wider scale in the United States shortly after the Second World War, where they were used as an alternative to common financial resources. The capital usually came from purely private resources and was designated as "private equity" while the venture capital was only understood as a source of financing small and medium size companies in the initial stage of their development. The venture capital investments experienced a real expansion in the United States only by the end of the 1970s and beginning of the 1980s namely in the industrial and 
consumer electronics, communication technologies and data transmission systems and in health services. During these from the investor's point of view successful years, also financial resources from other funds began to appear in the venture capital funds, e.g. from insurance companies, private pension funds, public trusts and the others (e.g. see Bance, 2004, p. 4).

In the eighties, venture capital investment funds extend their activities more and more frequently also outside the United States, in the beginning in countries of their former biggest business rivals - Japan and Germany. They actively focused especially on branches that represented the strongest competition to the Unites States, automobile industry and production of machinery consumption goods. Subsequently, the United States expanded their engagement also into all other economically advanced countries.

Development of European economy in the second half of the last century is closely connected with the existence of the European Union and mechanisms of its functioning and is considerably influenced by the internal redistribution processes. Therefore, the venture capital funds emerging in Europe during the eighties are mostly financially connected with supporting funds of the European Union largely determined for supporting small and medium size companies, regional development, environment protection and other activities of this kind. In 1984, European Venture Capital Association - EVCA was founded that associates European venture capital investors and represents their interests (e.g. see EVCA, 2007, p. 5).

Entry of the venture capital in the Czech Republic was only enabled by adopting legislation necessary for its functioning that took place only in middle of the 1990s. With respect to the wide range of needs of these transitional economic systems at that time, majority of investments were realized without goal-directed searching the particular sector or branch investment orientation (production, trade, services) or commodity sphere of business (agriculture machines, furniture, textile, telecommunication networks).

Primary activities of venture capital investors were gradually suppressed and the investor's output was usually implemented after a five to seven year engagement mostly with the same success rate that was common in other parts of the world. This recognition is somewhat surprising especially because aiming of investment activities and selection of the target commodity or service were performed rather randomly than conceptually, which is quite unusual for venture capital investments realised in other parts of the world. However, aiming of the investments corresponded to actual needs and trends of the Central and Eastern Europe economic systems of that time.

\section{Brief Characteristics of the Venture Capital Investments in the Period before and during the Crisis}

What were the prevailing venture capital investments in the world shortly before the crisis developed and what was their structure during the global crisis? What was the reaction of the venture capital investors in the world to the passed economic and financial crisis and how did this development differ in the Czech Republic? 
The venture capital funds and volume of their investments exhibited a regular year growth of $7-12 \%$ at the beginning of the millennium and in 2007, when the first signs of the imminent global financial crisis occurred, they reached a record-breaking volume of 493 respectively USD 309 billion . During the following two critical years, the volume of funds and investments dramatically dropped down to 150 respectively USD 91 billion, which did not considerably change in the next year (see Chart 1):

\section{Chart 1}

\section{Global Private Equity Investments and Funds Raised 2006-2010 in bn of USD}

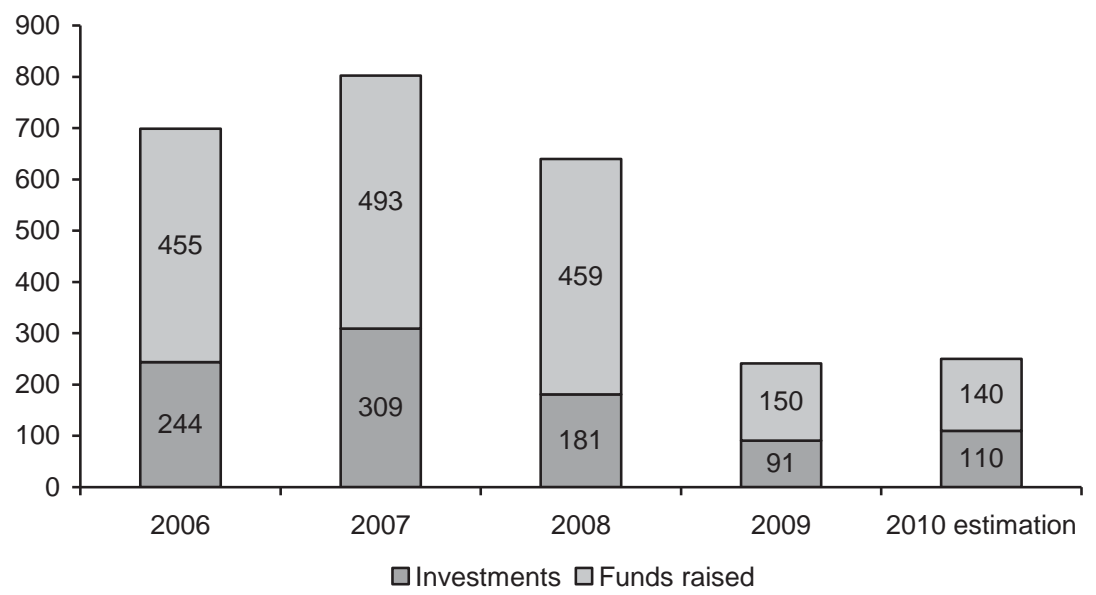

Source: The City UK, Private Equity 2010

The USA and some economically developed European countries (Great Britain, France and Germany) remained to be the traditional target countries of the venture capital funds and their investments. Switching of interest from Anglo-Saxon countries to perspective markets (the so-called emerging markets) of South-East Asia, namely India, China, Singapore and Malaysia expected by some experts (e.g. TheCityUK, p. 2), did not come true during the crisis years (see Chart 2).

However, the actual development proved that the volume of funds and investments in Asia could shortly overtake the formerly second regional recipient of investments Europe. Experts judge that thanks to perspective changes in its economy the Russian federation could also shortly join these countries (e.g. see Pricewaterhouse Coopers, 2008 , p.11). The volume of the realised venture capital investments here is in the meantime still insignificant but new promising opportunities are emerging namely in the mining industry and power engineering. By expanding its orientation to the above territories, China, India, South Korea, Singapore and in future perhaps also Russia, the venture capital investments gain a new, global dimension. 
Chart 2

Regional Breakdown of Venture Capital Investments in \%

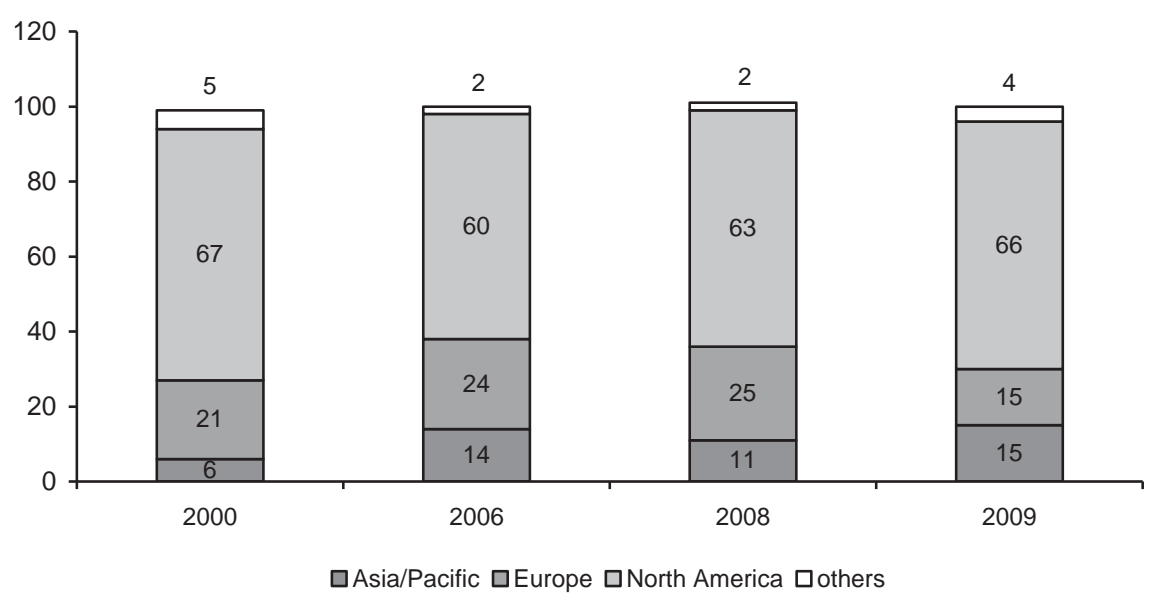

Source: The City UK, Private Equity 2010

Another convincing evidence of globalisation also is comparison of the qualitative aspects of entry and output of the venture capital in the company in the past and at present. In the past years, the venture capital entries were frequently orientated to small and medium companies for initiating their business activities or developing that on the local or regional level. If venture capital enters the companies at the same development level now, it usually leaves it at the moment of gaining or just having gained the global competency. This fact is also confirmed by common extension of the continuance time of the venture capital in the target company from the average 5.5 years experienced on the break of millennium to the actual 6.2 years. ${ }^{1}$

If we should compare the capital structure of funds carrying their business in Europe and North America, a typical high ratio of capital from institutional resources is typical for European funds, while capital coming from individual investors is dominant in the North America funds. The structure based on the origin of the capital of newly established European funds of the venture capital in Europe in 2009 was the following (see Chart 3).

Investment funds active in the Czech Republic and in the other Central and East European countries as well, have a similar structure. From the global point of view, these countries take a less important position in the global economy, which is reflected in the corresponding frequency and volume of entries of the venture capital investors. On the one hand, majority of these countries offer to the global and European economy a favourable geographical distance, educated and economically strengthening work force and advantage of their membership in the EU, however many factors negatively affecting the possibility of entry of the venture capital in these countries has not been eliminated.

1 Estimation was made by International Financial Services London, 2008 


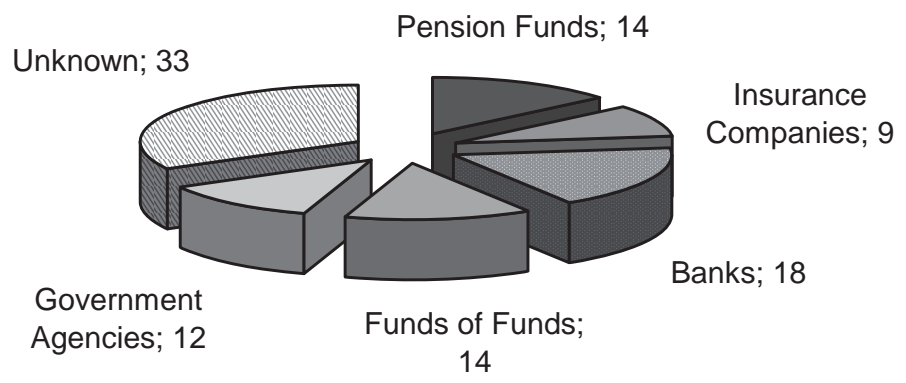

Source: The City UK, Private Equity 2010

\section{Evaluation of Quality of Tax and Legal Environments Necessary for Entry and Functioning of the Venture Capital}

EVCA (European Private Equity and Venture Capital Association) has a "Benchmarking European Tax and Legal Environments" study periodically elaborated that is focused on evaluation of quality of tax and legal environments necessary for entry and functioning of the venture capital in individual member countries of the association. ${ }^{2}$ Evaluation of conditions for entry and functioning of the venture capital is carried out from the capital investor's point of view and detail focused on three target groups:

- venture capital investors and investment funds,

- investee companies,

- management of investment funds and investees.

The evaluation showed that the optimal environment for the venture capital investment is in those countries that are their long-term recipients (e.g. see EVCA, 2008, p. 9). Evaluation of mentioned countries in the monitored period ranges from 1.2 to 1.4 (see Table 1).

The Czech Republic with its evaluation of 2.40 gradually sunk down to the last position of the monitored countries and out of the European countries currently has the least favourable environment for entry and functioning of the venture capital. ${ }^{3}$

Evaluation of the Czech Republic is negatively influenced by a number of facts that are generally perceived by public as brakes of business activities and that are results of prolonged instability of the home political arena. The problems are also caused namely by permanent postponing the realisation of basic conceptual reforms of the pensions scheme,

2 To evaluate the quality of the entrepreneurial environment, qualification scale from 1 to 3 (from the more favourable to the less favourable position) is used in the analysis.

3 Slovakia is almost in a similar position and its evaluation 2.33 is only slightly more favourable due to the very similar economical and political problems. 
which according to experts can in future lead also to general instability of the home economic systems. Based on the repeated official and unofficial statements of various political representatives, we can even be afraid that the integrated and well-considered concept of reforms in these countries has not yet been developed.

Table 1:

Tax and Legal Environment for the Development of Venture Capital in Countries Assessed (1 = More Favourable, 3 = less favourable position)

\begin{tabular}{|l|c|c|c|c|}
\hline Country & $\mathbf{2 0 0 8}$ & $\mathbf{2 0 0 6}$ & $\mathbf{2 0 0 4}$ & $\mathbf{2 0 0 3}$ \\
\hline France & 1.23 & 1.36 & 1.89 & 2.09 \\
\hline United Kingdom & 1.45 & 1.46 & 1.26 & 1.20 \\
\hline Netherlands & 1.63 & 1.60 & 1.76 & 1.79 \\
\hline Hungary & 1.84 & 1.83 & 1.86 & Not evaluated \\
\hline Average Europe & 1.85 & 1.84 & 1.97 & 2.03 \\
\hline Poland & 1.95 & 2.16 & 2.13 & Not evaluated \\
\hline Germany & 2.18 & 2.15 & 2.37 & 2.41 \\
\hline Slovakia & 2.33 & 2.17 & 2.49 & Not evaluated \\
\hline Czech Republic & 2.40 & 2.21 & 2.12 & Not evaluated \\
\hline
\end{tabular}

Source: EVCA - Benchmarking European Tax and Legal Environments, 2008

The remaining problem is a number of limiting restrictions in the business activities of pension insurance companies and their funds but also commercial insurance companies resulting from edict of Council No. 2003/41/EC. Obligation to tax management fees and non-existence of tax exemptions for entry of the venture capital investment are also negatively perceived by the venture capital investors. At this point, however, the EVCA evaluation is not hundred percent unbiased because the same types incentives as those for other entries can be used in these countries.

The only positive point of evaluation by EVCA should be support of endeavour for interconnection home research and development centres with entrepreneurs both at home and in abroad (e.g. see EVCA, 2008, p. 9). However, some system supporting independent research workers and transport of technologies, namely when establishing innovative companies, is locally missing. The tax burden of private persons from the side of investors is considered as reasonable. Tax burden of earnings from business activities and taxes of management fees are considered as reasonable.

\section{Overview of Measures Supporting Private Equity Investments in Europe as well as in the Czech Republic}

It was expected that inflow of venture capital investments to Europe and to the Czech Republic as well will bring realisation of intentions of the EU Committee summarised in 
Notice No. 853 (e.g. see Communication from the Commission No. 853 of December 21, 2007). This material defines the existing obstacles for easier and more effective utilisation of the venture capital funds in the cross-border co-operation and it recommends steps leading to their elimination. The committee sees a positive contribution of the venture capital investments in small and medium size companies namely in that they create new labour opportunities and help to introduce new technologies while considering environment. However, similarly as EVCA, the committee sees problems of current venture capital investments namely in the frequent orientation on "buy in - buy out" operation, eventually their orientation on development or expansion of the business activity, while their orientation on the starting or pre-starting phase of the business, which is usual for example in the United States, occurs less frequently. It is just this type of investments that brings new, creative and innovative technologies and thus increases dynamism of economic growth namely in small and medium size business. The reason of this condition is namely the character and origin of the financial resources in individual investment funds. A substantial part of financial resources of European investment funds come from the EU redistribution processes that are targeted rather on solving particular, already existing problems instead of on venturesome business experiments.

Another problem of the European venture capital market still remains its outstanding legislation and tax disunity that brings unnecessarily high costs connected with its entry and functioning. The venture capital investments are realised in the European Union in 27 various entrepreneurial environments in total that feature various political, economic, legal, cultural and historical conditions and traditions (e.g. see Groh, Liechtenstein, Canela, 2007, p. 14).

Naturally, realisation of the venture capital investments bears on close relations between investors and entrepreneurs, which create possibilities to utilise good knowledge of the local entrepreneurial environment. However, the current experience also shows that the venture capital reaches exceptionally good results namely in proximity of entrepreneurial centres, research centres or universities where new ideas and entrepreneurial opportunities emerge. It is just this sector in the European Union in which there is a strong unevenness in geographical distribution of these items when individual states, region and localities show considerable quantitative and qualitative differences in this aspect (e.g. see Sato, 2010, p. 126). The Committee intends to eliminate these differences by means of supporting reforming programs, for example by means of the existing operation program "Business and Innovation" or by means of activities following up the project "Jeremie". ${ }^{4}$

\section{Conclusion}

What conclusions can be drawn from the analysis of the present development, actual condition and expected trends of development of the venture capital investment and

4 JEREMIE (Joint European Resources for Micro to Medium Enterprises) has been developed in cooperation with the European Commission and offers to the EU Member States the opportunity to finance small and medium-sized enterprises by means of private equity funds, loans or guarantees. 
what measures should be adopted to support their utilisation and secure their return and success: Naturally, the venture capital investments cannot substitute financing in its traditional forms (e.g. supplier and bank credits, leasing, etc.) and cannot be considered as a tool enabling overall revitalization of the global or local economy. They can, however, be used to stimulate or realize selected kinds of business activities targeted for example on research, development, production and distribution of new products, technologies and services or on realization of individual specific projects with local or regional utilization. To improve investment conditions in the Czech Republic, it is necessary to gradually eliminate the existing obstructions, namely to:

- Unify and simplify legislation and tax conditions for placing and functioning the financial capital in general and thus also the venture capital.

- Improve the legal frame and fiscal regulations related to venture capital investments and to harmonize them with legal and fiscal regulations of other member countries of the European Union.

- Reduce investment and operating costs, to eliminate risks connected with investment activities (e.g. see Hnilica, 2009, p. 56) to enable investors to reach higher capital yields.

- Eliminate or at least to alleviate tax obstacles, to secure transparency of tax reporting and to prevent double taxation.

The above steps have to be understood not only as a suitable but also as a necessary "incentive" for a more profound entry of venture capital investors in the Czech Republic and as another suggestion within the measures leading to alleviation of impacts of the global financial and economic crisis.

\section{References:}

Bance, A. (2004), "Why and How to Invest in Private Equity: An EVCA Special Paper." Zaventem.

Berkery, D. (2008), Raising Venture Capital for the Serious Entrepreneur, 1st edition, New York: McGraw-Hill.

Černohlávková, E., Sato, A., Taušer, J. aj. (2007), Finanční strategie v mezinárodním podnikání. 1. vyd. Praha : ASPI

Dubocage, E., Rivaud-Danset, D. (2006), Le capital - risque. Paris: Le découverte.

EVCA (2006, 2008), Benchmarking European Tax and Legal Environment, Brussels: European Private Equity and Venture Capital Association.

EVCA (2007), Guide on Private Equity and Venture Capital Entrepreneurs. Brussels: European Private Equity and Venture Capital Association.

EVCA (2006), Private Equity Funds Structures in Europe, Brussels: European Private Equity and Venture Capital Association.

EVCA (2006, 2007), European Private Equity Activity Survey, Brussels: European Private Equity and Venture Capital Association.

EVCA (2006-2010), Statistics, Brussels: European Private Equity and Venture Capital Association.

EVCA (2006-2010), Yearbooks, Brussels: European Private Equity and Venture Capital Association. 
EK (2007), Communication from the Commission No. 853 of 21.12.2007 Removing Obstacles to Cross-border Investments by Venture Capital Funds, Brussels.

Gregoriou, G. N., Kooli, M., KraeussI, R. (2007), Venture Capital in Europe. 1st edition, Oxford: Butterworth-Heinemann.

Groh, P., Liechtenstein, H., Canela, M. (2007), "Allocation Determinants of Institutional Investment in Venture Capital and Private Equity Limited Partnerships in Central Eastern Europe." Working Paper 691. IESE Business School. University of Navara.

Hnilica, J., Fotr, J. (2009), Aplikovaná analýza rizika. 1. vyd. Praha : Grada Publishing

Machková, H., Černohlávková E., Sato, A. a kol. (2010), Mezinárodní obchodní operace. 5. Vyd. Praha: Grada Publishing, 2010.

ICC (2009), Key Messages on the Global Economic Crisis. Brussels: International Chamber of Commerce.

IFSL (2008), Private Equity 2008. London: International Financial Services London.

Kortum, S.; Lerner, J. (2000), Assessing the Contribution of Venture Capital to Innovation, Santa Monica: Rand Journal of Economics.

PWC (2007), Private Equity Investments in Russia. Moscow: Pricewaterhouse Coopers.

PWC (2008), Global Private Equity Report. Pricewaterhouse Coopers, 2008.

Salesny, P. (2008), Private Equity in Central and Eastern Europe: Opportunities in an "Emerged" Market. Zurich: Private No. 3.

Taušer, J. (2005), "The Specific Aspects of SMEs Financing in the Czech Republic." Terni 22.09.2005 - 24.09.2005. In La creazione di imprese innovative. La creation denterprises innovantes. Terni : Stampa Tipolitogra Antolini, p. 223-228.

TheCityUK (2010), Private Equity 2010. London: TheCityUK Research Center.

Weidig, T., Mahonet, P-Y. (2004), Risk Profile of Private Equity. Luxembourg: Social Science Research Network.

Wooder, R. J. (2004), Global Venture Capital Transactions: Practical Approach. $1^{\text {st }}$ edition, The Hague: Wolters Kluwer Law \& Business. 